Article

\title{
An Intelligent Nanoscale Insulin Delivery System
}

\author{
Wei Wang ${ }^{1,2, \dagger}$, Ling Liao ${ }^{2, \dagger}$, Xiaobing Zhang ${ }^{1,3}$, Fan Lei ${ }^{4}$, Yaou Zhang ${ }^{1,2,3}$, Gan Liu ${ }^{5, *}$ and \\ Weidong Xie ${ }^{1,2,3, *(D)}$ \\ 1 Key Lab in Health Science and Technology, Division of Life Science \& Health, Graduate School at Shenzhen, \\ Tsinghua University, Shenzhen 518055, China; kappa33wei@live.com (W.W.); \\ zxb17@mails.tsinghua.edu.cn (X.Z.); zhangyo@sz.tsinghua.edu.cn (Y.Z.) \\ 2 Open FIESTA Center, Tsinghua University, Shenzhen 518055, China; 15602927350@163.com \\ 3 State Key Laboratory of Chemical Oncogenomics, Graduate School at Shenzhen, Tsinghua University, \\ Shenzhen 518055, China \\ 4 School of Pharmaceutical Sciences, Tsinghua University, Beijing 100084, China; leifan@mail.tsinghua.edu.cn \\ 5 School of Pharmaceutical Sciences (shenzhen), Sun Yat-Sen University, Guangzhou 510275, China \\ * Correspondence: liugan5@mail.sysu.edu.cn (G.L.); xiewd@sz.tsinghua.edu.cn (W.X.); \\ Tel.: +86-755-2603-6086 (W.X.) \\ + These authors contributed equally to this work.
}

Academic Editor: Angelina Angelova

Received: 15 October 2018; Accepted: 9 November 2018; Published: 11 November 2018

\begin{abstract}
Insulin injection relies on strict blood glucose monitoring. However, existing techniques and algorithms for blood glucose monitoring cannot be completed in a timely way. In this study, we have developed a new intelligent glucose-sensitive insulin delivery system to stabilize blood glucose levels in the body. This system does not require real-time detection of blood glucose. First, we successfully synthesized a nanoscale material called PAM-PAspPBA- $b$-PEG by using chemical methods. We then conducted TEM, DLS, and ${ }^{1} \mathrm{H}-\mathrm{NMR}$ analyses to characterize the physicochemical properties, such as size, molecular composition, and configuration of the nanomaterial. We verified the glucose responsibility of the insulin loading nanoscale material in vitro and evaluated its safety and effect on mice in vivo. Results showed that insulin-loaded PAM-PAspPBA- $b$-PEG is glucose-sensitive, safer and more effective than regular insulin injection. This study provides a basis for future development of smart insulin delivery systems.
\end{abstract}

Keywords: insulin; diabetes; drug delivery; PAM-PAspPBA- $b$-PEG

\section{Introduction}

The current prevalence of diabetes worldwide is high, and the number of diabetic patients is expected to increase to 592 million by 2035 [1]. Diabetes causes many serious complications and a huge economic burden to the patients' family and society. Severe diabetes is treated by insulin injection [2]. However, current insulin injection protocols cannot fundamentally meet the actual requirements of diabetic patients because of their daily blood glucose fluctuation [3]. Insulin delivery relies on a real time-continuous glucose monitoring technology in case of hypoglycemic effects [4]. Moreover, existing glucose monitoring techniques still have many limitations.

Self-regulated insulin delivery is currently under development and has emerged as an important direction of future insulin administration [5]. This study aims to develop a new intelligent glucose-sensitive insulin delivery system that does not require real-time detection of blood glucose. We design a novel nanoscale polymer material named dendrimer polyamidoamine (PAM)-polyaspartic acid (PAsp) phenylboronic acid (PBA)-polyethylene glycol (PEG) (Figure 1). The material could package insulin in the core after self-assembly and exhibits glucose responsitivity, that is, it could mimic a physiological insulin release system when the blood glucose level changes. The self-assembled material has an 
excellent drug loading, as previously described [6]. Insulin is hydrophobic in the neutral solution and also can bind to the hydrophobic core of the material by Van der Waals' force. When the material was coupled with phenylboronic acid (PBA) it demonstrated glucose responsiveness [6]. When the glucose concentration increased to some extent, the PBA contained in the material would become hydrophilic, weakening the van der Waals' forces between the insulin and the material. The structure of the material would change and insulin might easily escape from the material, so we speculated that insulin entrapped inside the material would be easily released in a high glucose state.

\section{Results}

\subsection{Identification of Nanoparticles}

We synthesized PAM-PAspPBA- $b$-PEG in four chemical reaction steps. The chemical structure of the dendritic copolymer PAM-PAspPBA- $b$-PEG was determined by ${ }^{1} \mathrm{H}$-nuclear magnetic resonance (NMR) analysis (Figure 1). PAM-poly( $\beta$-benzyl-L-aspartate)(PBLA)- $\mathrm{NH}_{2}$ was synthesized according to the reference [6]. The degree of polymerization of PBLA in each PAM-PBLA-NH $\mathrm{N}_{2}$ was calculated by comparing the peak areas of $\mathrm{a}$ and $\mathrm{b}$ with $\mathrm{c}$ and found to be 480 (Figure 1A). The average number of PBLA units initiated by each amine was 15 because each polyamidoamine(PAMAM)-G3 dendrimer contains 32 primary amines. As shown in Figure 1B, peak e represents the methylene of PEG (-OCH $\left.\mathrm{CH}_{2-}: \delta=3.7 \mathrm{ppm}\right)$, indicating successful grafting of $\mathrm{PEG}_{45}$ on the dendritic polymer. The number of PEG units grafted on each copolymer was quantified by comparing the proton ratios of the methylene units of PEG (peak e) with the methylene units of PBLA (peak c) and found to be 30, which confirms that nearly all PBLA blocks were grafted with PEG. After acid hydrolysis, the ${ }^{1} \mathrm{H}-\mathrm{NMR}$ signal that corresponds to the benzyl group and the identical degree of polymerization (DP) between PAsp and PBLA segments disappeared, indicating the complete deprotection of $\beta$-benzyl-L-aspartate (BLA) without breakage of the PAsp backbones. Finally, PAM-PAspPBA- $b$-PEG was synthesized by modifying APBA on the side -COOH group of the PAsp block. The medication degree, which is peak intensity ratio between the phenyl protons $(\mathrm{d})$ and methylene protons of PEG (c), was calculated to be $71 \%$. The molecular weight of PAM-PAspPBA- $b$-PEG was calculated as about $160 \mathrm{kD}$.

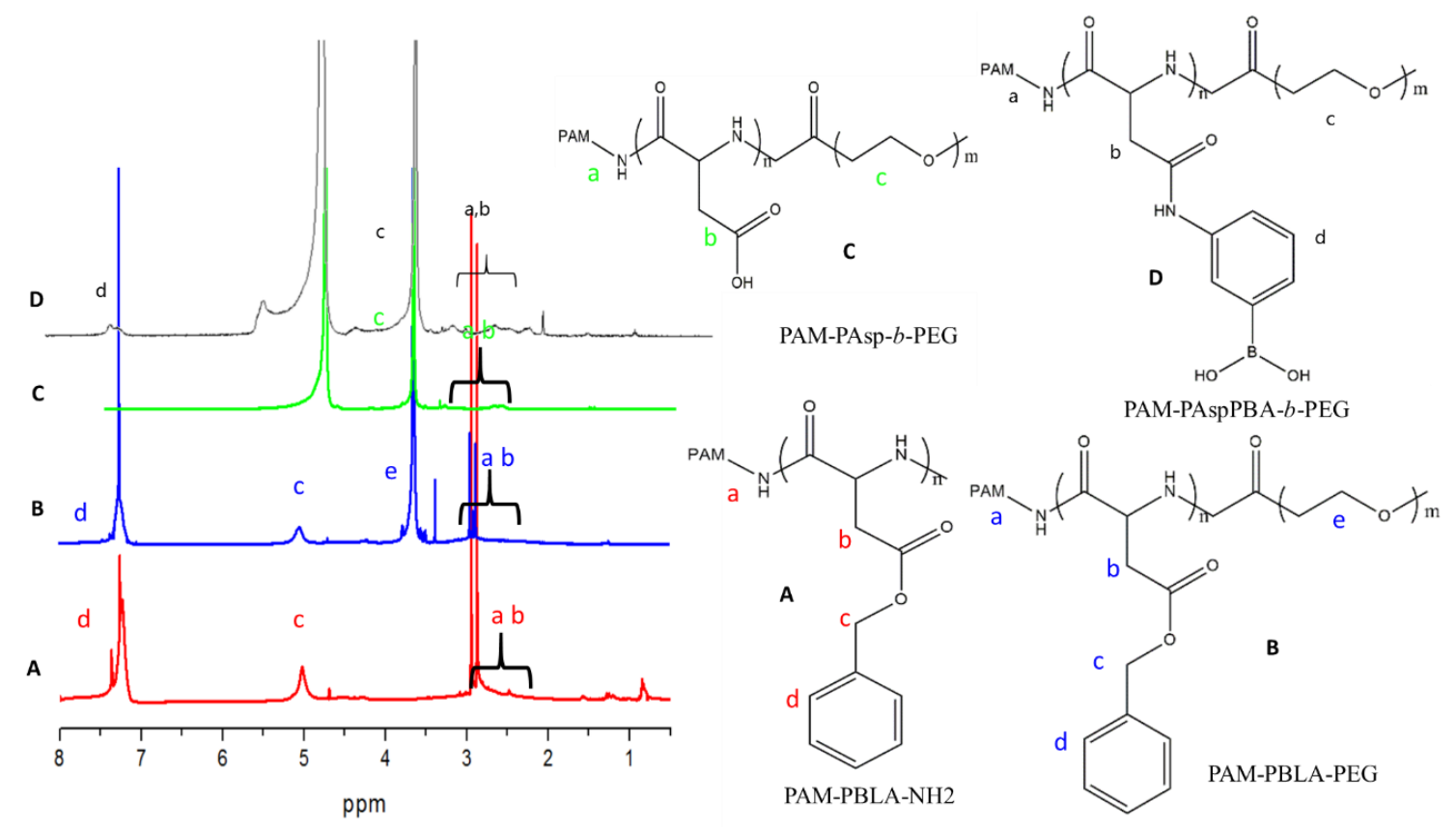

Figure 1. ${ }^{1} \mathrm{H}-\mathrm{NMR}$ spectra of (A) PAM-PBLA $480-\mathrm{NH}_{2}$, (B) PAM-PBLA $480-b-\left(\mathrm{PEG}_{45}\right)_{30}$, (C) PAMPAsp $_{480}-b-\left(\mathrm{PEG}_{45}\right)_{30}$, and (D) PAM-(Asp $\left.0.29-c 0-\mathrm{AspPBA}_{0.71}\right)_{480}-b-\left(\mathrm{PEG}_{45}\right)_{30}$. 


\subsection{Characterization of Nanoparticles}

The size of the new material PAM-PAspPBA- $b$-PEG was determined to range from $80 \mathrm{~nm}$ to $150 \mathrm{~nm}$ based on transmission electron microscopy (TE, Figure 2), which indicates that PAM-PAspPBA-b-PEG contains nanoparticles. The loading efficiency is $14.4 \%$ while the entrapment efficiency is $56.1 \%$. We also tested the stability of the nanoparticle within 7 days at $4{ }^{\circ} \mathrm{C}$, no significant difference of size was observed.

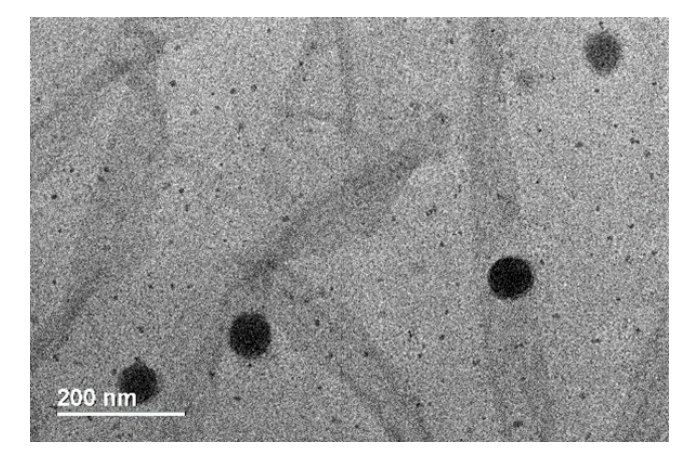

Figure 2. TEM image for PAM-PAspPBA- $b$-PEG.

\subsection{Glucose Response Study}

To evaluate the glucose responsiveness of PAM-PAspPBA- $b$-PEG, dynamic light scattering (DLS) showed that the sizes of both PAM-PAspPBA- $b$-PEG and insulin-loaded PAM-PAspPBA- $b$-PEG after the addition of glucose $(20 \mathrm{mM})$ for $30 \mathrm{~min}$ increased compared with that before the addition of glucose (Figure 3), which indicates that the nanoparticle of PAM-PAspPBA- $b$-PEG has a slight glucose responsiveness.

A

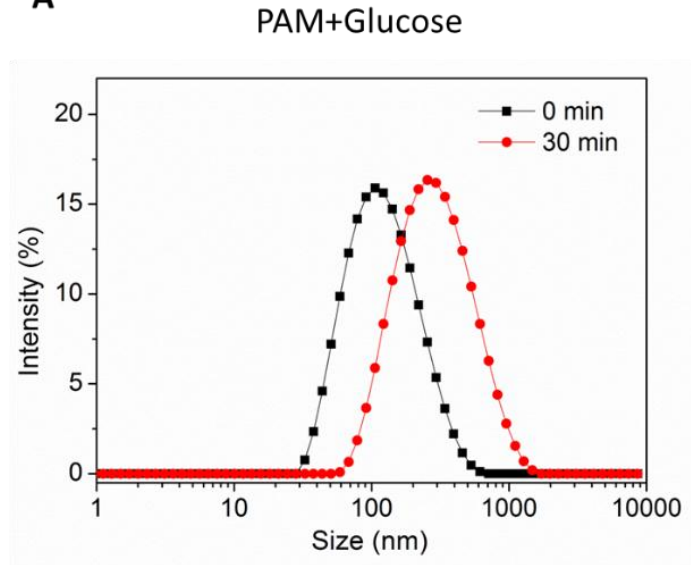

$122 \rightarrow 255 \mathrm{~nm}$

\section{B}

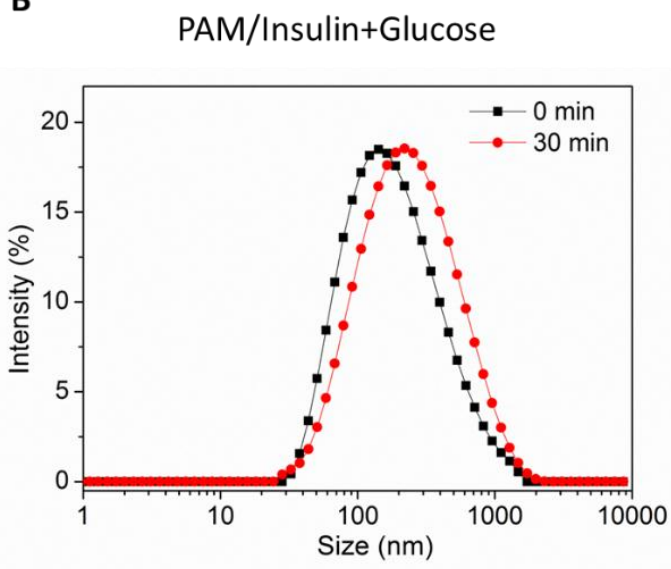

$142 \rightarrow 220 \mathrm{~nm}$

Figure 3. Changes of sizes of PAM-PAspPBA-b-PEG and insulin-loaded PAM-PAspPBA- $b$-PEG after adding glucose determined by DLS. PAM-PAspPBA- $b$-PEG (A) and insulin-loaded PAM-PAspPBA- $b$-PEG (B) dissolved in $20 \mathrm{mM}$ glucose solution (PBS, $\mathrm{pH}=7.4$ ) at $0 \mathrm{~min}$ and $30 \mathrm{~min}$.

Furthermore, we used phosphate buffer saline (PBS) and fetal bovine serum (FBS) that contained different glucose concentrations (0-30 mM), and we determined that the insulin release in the solutions. We found that glucose dramatically increased insulin release in PBS solution contained glucose almost in a dose-dependent manner (Figure 4A,B). Also, high concentration of glucose showed a significant increase in insulin release in the serum compared with the low concentration of glucose (Figure 5A,B). 
A

PBS

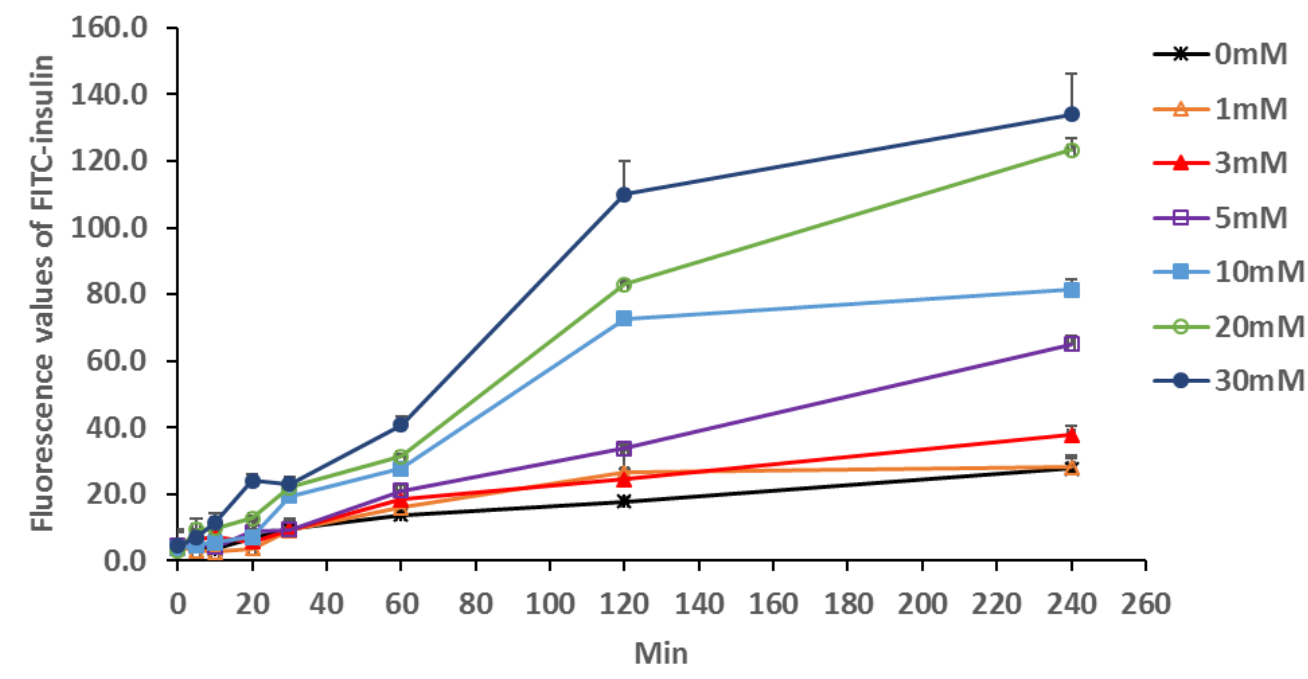

B

PBS

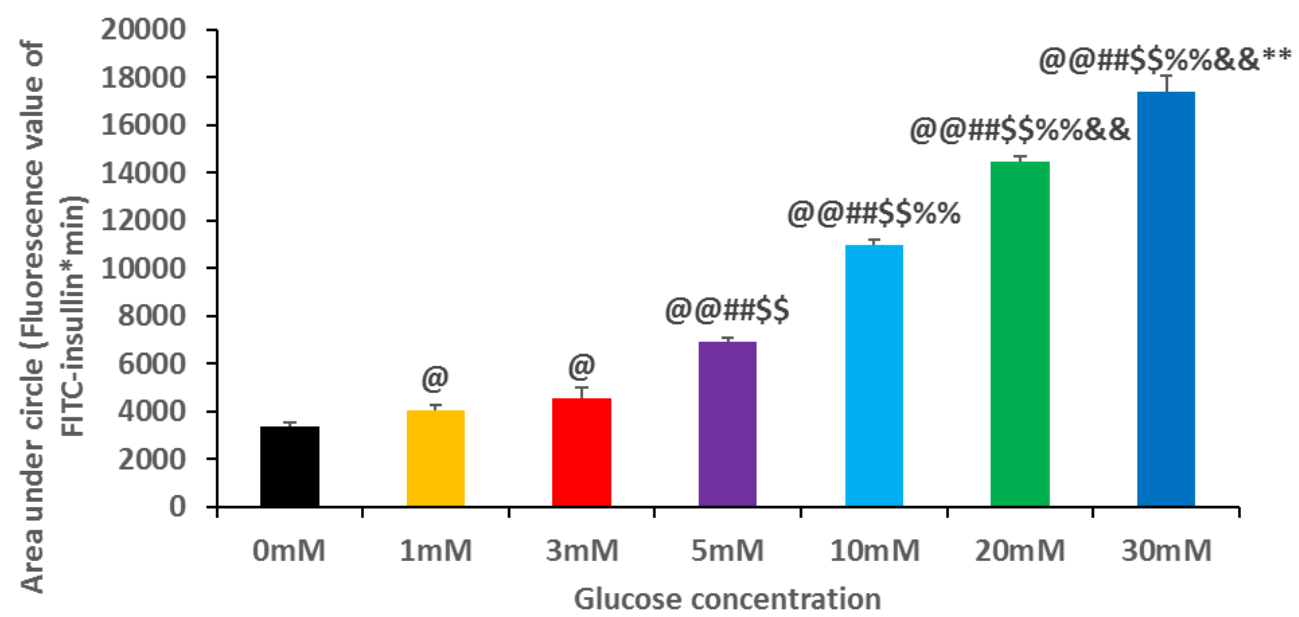

Figure 4. Insulin release in PBS (A) with different glucose concentrations. Area under circles of fluorescence values of fluorescein isothiocyanate (FITC)-insulin with different glucose concentrations within 240 min were calculated by the formulation ' $[(F 0+F 5) \times 5+(F 5+F 10) \times 5+(F 10+F 20)$ $\times 10+(\mathrm{F} 20+\mathrm{F} 30) \times 10+(\mathrm{F} 30+\mathrm{F} 60) \times 30+(\mathrm{F} 60+\mathrm{F} 120) \times 60+(\mathrm{F} 120+\mathrm{F} 240) \times 120] \times 1 / 2 ;$ Fn, Fluorescence value at $\mathrm{n} \min , \mathrm{n}=0,5,10,20,30,60,120$ or 240]', respectively (B). FITC-insulin loaded PAM-PAspPBA- $b$-PEG dissolved in PBS (pH 7.4) with $0,1,3,5,10,20$ or $30 \mathrm{mM}$ final glucose concentration. The experiment is repeated thrice. Data were represented as mean \pm S.D.; $@ P<0.05$, $@ @ P<0.01$ vs. $0 \mathrm{mM} ; \# \# P<0.01$ vs. $1 \mathrm{mM} ; \$ \$ P<0.01$ vs. $3 \mathrm{mM} \% \% P<0.01$ vs. $5 \mathrm{mM} ; \& \& P<0.01$ vs. $10 \mathrm{mM} ;{ }^{* *} P<0.01$ vs. $20 \mathrm{mM}$. 
A

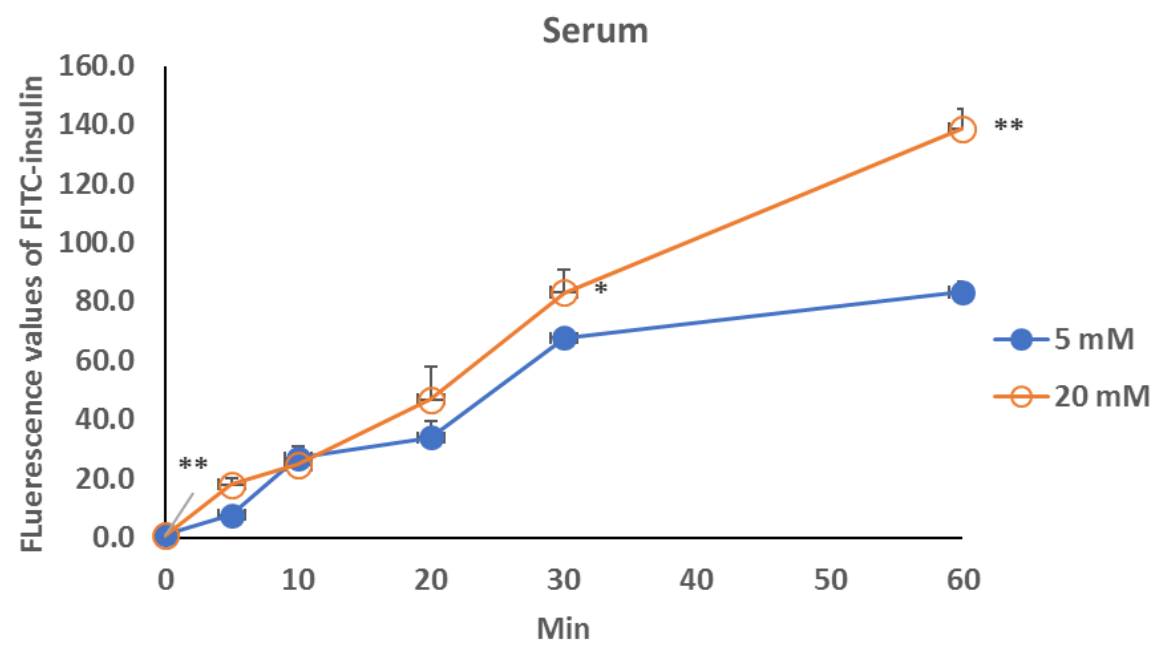

B

Serum

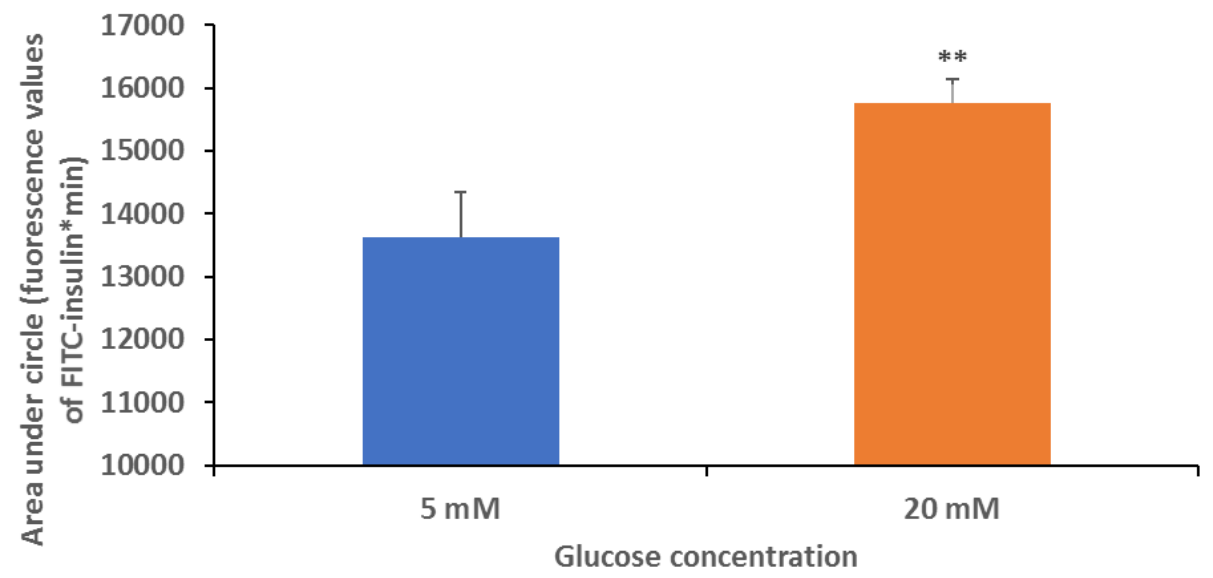

Figure 5. Insulin release in serum (A) with different glucose concentrations. Area under circles of fluorescence values of FITC-insulin within $60 \mathrm{~min}$ in serum were calculated by the formulation '[(F0 + F5) $\times 5+(\mathrm{F} 5+\mathrm{F} 10) \times 5+(\mathrm{F} 10+\mathrm{F} 20) \times 10+(\mathrm{F} 20+\mathrm{F} 30) \times 10+(\mathrm{F} 30+\mathrm{F} 60) \times 30] \times 1 / 2 ;$ Fn, Fluorescence value at $\mathrm{n}$ min, $\mathrm{n}=0,5,10,20,30$ or 60]' (B). FITC-insulin-loaded PAM-PAspPBA- $b$-PEG dissolved in serum ( $\mathrm{pH}$ 7.4) with $5 \mathrm{mM}$ or $20 \mathrm{mM}$ final glucose concentration. The experiment is repeated thrice. Data were represented as mean \pm S.D., ${ }^{*} P<0.05$, ${ }^{* *} P<0.01$ vs. $5 \mathrm{mM}$ (or at respective time points, see A).

\subsection{Safety and Effect Evaluation}

To test the safety of the insulin-loaded PAM-PAspPBA-b-PEG in mice, we determined that the injection of insulin-loaded PAM-PAspPBA- $b$-PEG did not cause death in the normal mice, whereas the injection of pure insulin at identical dosage caused the death of $50 \%$ mice due to hypoglycemia (Figure 6A). In the diabetic mice, there were no survivals for pure insulin treatment while insulin-loaded PAM-PAspPBA- $b$-PEG at identical dosage could cause $60 \%$ mice survived. 
A

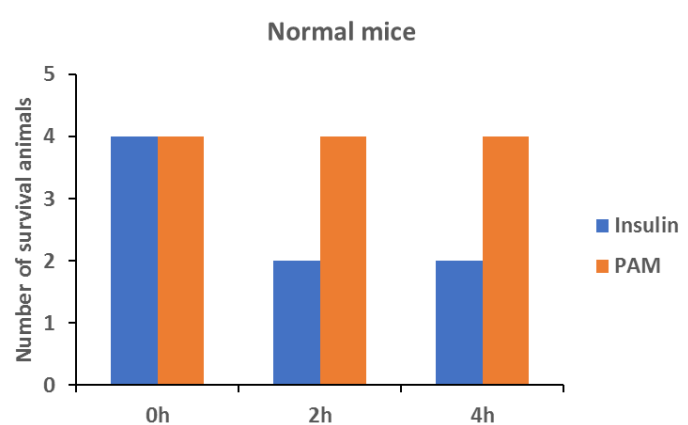

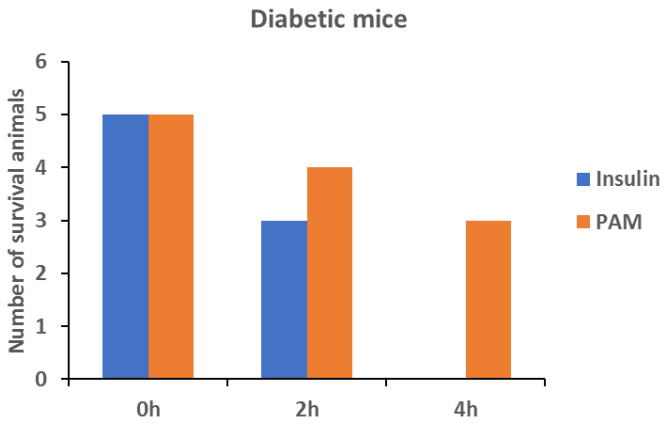

C

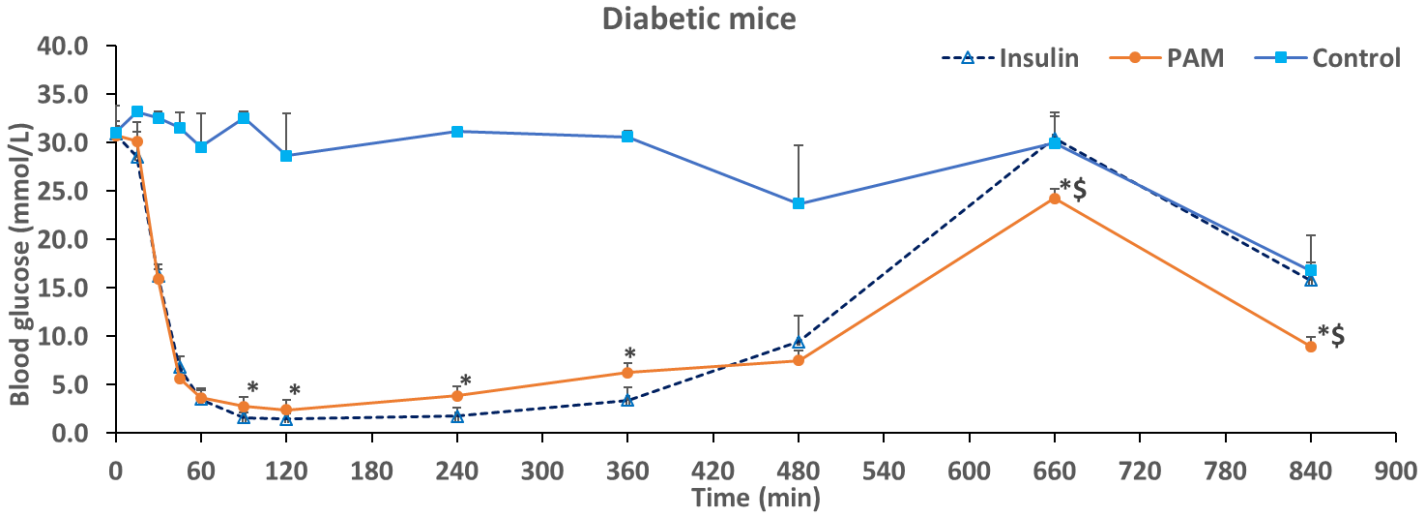

Figure 6. Safety (A and B) and effect (C) evaluation of insulin-loaded PAM-PAspPBA- $b$-PEG in normal and diabetic mice. Pure insulin-treated (Insulin) and insulin-loaded PAM-PAspPBA- $b$-PEG-treated (PAM) animals received a subcutaneous injection of insulin at identical dosage of 0.25 (for effect experiment) or $1.2 \mathrm{mg} / \mathrm{kg}$ (for safety experiment), $n=4-5$. For diabetic mice, data were represented as mean \pm S.D, ${ }^{*} P<0.05,{ }^{* *} P<0.01$ vs. Insulin, ${ }^{\$} P<0.05$ vs. diabetic control (Control).

Subsequently, we evaluated whether the insulin-loaded PAM-PAspPBA- $b$-PEG had a similar effect to pure insulin in diabetic mice in hyperglycemic state. There was no significant difference observed between two groups within $60 \mathrm{~min}$ of the injection, an early stage after insulin injection (Figure 6C). However, pure insulin injection had a lower glucose level compared with insulin-loaded PAM-PAspPBA- $b$-PEG at 90 and 120 min of the injection, which might explain why pure insulin treated mice were easily dead caused by severe hypoglycemic response. Intriguingly, in the late stage of injection, insulin-loaded PAM-PAspPBA-b-PEG still showed significant decrease in blood glucose while pure insulin treatment did not exert glucose-lowering effects at 660 and $840 \mathrm{~min}$. Obviously, the insulin-loaded PAM-PAspPBA- $b$-PEG at identical insulin dosage had a better blood glucose control ability compared with pure insulin in diabetic mice.

\subsection{Biocompatibility Tests}

We conducted biocompatibility tests by cytotoxicity experiments in RAW264.7 cells. There was no significant cytotoxicity observed after adding PAM-PAspPBA- $b$-PEG within $500 \mu \mathrm{g} / \mathrm{mL}$ (final concentration, Figure 7A) by using a 3-(4,5-dimethylthiazol-2-Yl)-2,5-diphenyltetrazolium bromide (MTT) assay. 
A

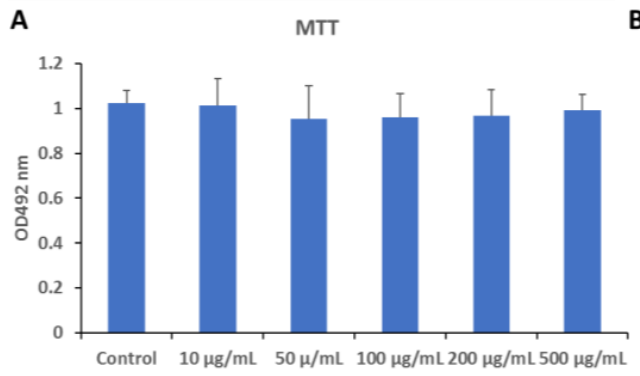

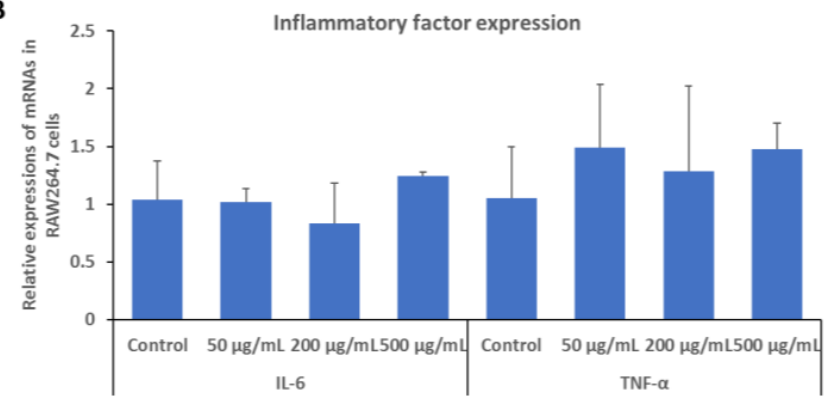

Figure 7. Cytotoxicity assay (A) by MTT method and inflammatory factor expressions (B) by RT-PCR analysis in RAW264.7 cells.

Also, we did not see significant changes of inflammatory factor expression after exposing into PAM-PAspPBA- $b$-PEG (Figure 7B) by RT-PCR analysis. Considering that the dosage of insulin was not more than $24 \mathrm{IU}$ (about $1 \mathrm{mg}$ ) per day [6], according to the loading efficiency of insulin (14.4\%), in human, the estimated dosage of PAM-PAspPBA-b-PEG was not more than $6 \mathrm{mg}$ per day. The blood volume of an adult was usually $4-5 \mathrm{~L}$, so the estimated concentrations of PAM-PAspPBA- $b$-PEG were not more than $2 \mu \mathrm{g} / \mathrm{mL}$ per day in blood, which may be far less than $500 \mu \mathrm{g} / \mathrm{mL}$. Furthermore, the micelle contained poly(amino acids) that would be degraded and metabolized gradually. Taken together, there is no indication that the micelles cause toxicity or inflammatory stimulation responses and they seem safe to serve as a vehicle.

\section{Discussion}

Type 1 diabetes and severe type 2 diabetes depend on insulin injection. However, insulin injection on those patients is difficult because the rapid detection of blood glucose is complicated. Self-regulated insulin delivery systems that simulate the physiological response are well-developed [7]. Synthetic PBA-based polymeric particles have better stability and less immunogenicity than glucose oxidase and lectin and have received considerable attention [8].

Previous studies have proved that the self-assembled PBA-based polymeric micelles from poly(ethylene glycol)-block-poly(acrylic acid-co-acrylamidophenylboronic acid) (PEG-b-(PAA-co-PAAPBA)) exhibit glucose-responsive release of insulin under physiological conditions [9]. However, a simple core-shell structure cannot achieve repeated on-off release due to its disassembly in response to glucose. Then, self-assembled complex micelles from two types of diblock copolymers, namely, poly(ethylene glycol)-b-poly(aspartic acid-co-aspartamidophenylboronic acid and poly( $\mathrm{N}$-isopropylacrylamide)$b$-poly(aspartic acid-co-aspartamidophenylboronic acid) [6], have been developed to achieve repeated glucose-responsive on-off insulin release. However, they still require optimization due to their complicated synthesis and low biocompatibility.

Dendritic polymeric micelles fabricated from multiarm star block copolymers have attracted considerable attentions due to their excellent in vivo stability and other advantages, such as no surrendered degradability and drug release profiles and narrow disperse dimensions. PAMAM dendrimers, which are the first commercialized dendrimer family, have good biocompatibility, structural control, functionalizability, and low cost, which are usually used in nanotechnology and drug development [10-12]. They are widely utilized as macroinitiators in synthesizing dendritic polymeric micelles due to their numerous tailorable terminal functional groups. In this study, we synthesized a new polymeric material named PAM-PAspPBA- $b$-PEG based on PAMAMs through a simple chemical synthesis. The core-shell structure has considerable insulin load, good biocompatibility, and low cost. Obviously, the insulin-loaded PAM-PAspPBA- $b$-PEG showed comparable glucose responsiveness.

Regular insulin injection can easily cause a hypoglycemic event, shock, and even death if blood glucose cannot be closely monitored. Approximately 25\% diabetic American patients have a low blood glucose level upon hospitalization [13]. Here, we determined that insulin-loaded 
PAM-PAspPBA- $b$-PEG did not easily cause a hypoglycemic death in mice due to low insulin release, which indirectly indicates that the insulin-loaded PAM-PAspPBA-b-PEG is safer. This result in vivo enhances a concept that insulin-loaded PAM-PAspPBA- $b$-PEG has less insulin release compared with pure insulin when blood glucose is low. However, we determined that the insulin-loaded PAM-PAspPBA- $b$-PEG has a similar effect to pure insulin in a hyperglycemic state, which indirectly indicates that insulin-loaded PAM-PAspPBA- $b$-PEG has similar release to pure insulin in the case of hyperglycemia. Blood glucose fluctuation can cause serve damage to the human body in diabetic individuals [14]. Intriguingly, insulin-loaded PAM-PAspPBA-b-PEG has a better effect on preventing the development of hypoglycemia or hyperglycemia than pure insulin in diabetic animals, which suggests that insulin-loaded PAM-PAspPBA- $b$-PEG might have a better control over blood glucose fluctuation than pure insulin and show a promising application in diabetic individuals.

\section{Materials and Methods}

\subsection{Materials}

Dendrimer PAMAM G3 was purchased from Weihai CY Dendrimer Technology Co. Ltd., China. $\beta$-Benzyl-L-aspartate N-carboxyanhydride (BLA-NCA) was obtained from Nanjing Chemlin Chemical Industry Co., Ltd. (Nanjing, China). PEG-SCM was provided by Wuhu Ponsure Biotechnology Co. Ltd. (Wuhu, China). 3-Aminophenylboronic acid (APBA), trifluoroacetic acid $\left(\mathrm{CF}_{3} \mathrm{COOH}\right)$, $N, N$-dimethylformamide (DMF), and $N$-(3-dimethylaminopropyl)- $N^{\prime}$-ethyl-carbodiimide hydrochloride (EDC) were purchased from Sigma-Aldrich (St. Louis, MO, USA). 3-(4,5-Dimethylthiazol-2-yl)-2,5diphenyltetrazolium bromide (MTT) was purchased from Amresco (Radnor, OH, USA). Insulin was obtained from Beijing Dingguo Changsheng Biotechnology Co. Ltd. (Beijing, China). FBS was purchased from PAN-Biotech (Aidenbach, German). Dulbecco's Modified Eagle Medium (DMEM) was purchased from Thermo Fisher Scientific (Waltham, MA, USA).

\subsection{Synthesis of Polymer}

\subsubsection{Synthesis of PAM-PBLA- $\mathrm{NH}_{2}$}

First, PAM-PBLA- $\mathrm{NH}_{2}$ was synthesized by anionic polymerization reaction between PAMAM-G3$\mathrm{NH}_{2}$ and BLA-NCA. Briefly, BLA-NCA (3 g) was dissolved in the mixture solution of DMF $(30 \mathrm{~mL})$ and dichloromethane $\left(\mathrm{CH}_{2} \mathrm{Cl}_{2}, 3 \mathrm{~mL}\right)$ at $80^{\circ} \mathrm{C}$. Then, PAMAM-G3- $\mathrm{NH}_{2}$ solution $(0.9 \mathrm{~g}$, dissolved in $20 \%$ methanol) was added in BLA-NCA solution. The reaction mixture was stirred for 3 days at $25^{\circ} \mathrm{C}$ under dry nitrogen atmosphere. Subsequently, the reaction mixture was precipitated in 10 -fold excess of precooled $\left(-20^{\circ} \mathrm{C}\right)$ diethyl ether $(300 \mathrm{~mL})$. Then, the diethyl ether in the solution was evaporated to driness, and the remaining precipitate was PAM-PBLA- $\mathrm{NH}_{2}$.

\subsubsection{Synthesis of PAM-PBLA-PEG}

Second, PAM-PBLA-PEG was synthesized by amidation reaction between PAM-PBLA-NH $\mathrm{NH}_{2}$ and PEG-SCM. Briefly, PAM-PBLA-NH $2(1 \mathrm{~g})$ was dissolved in DMF $(10 \mathrm{~mL})$. Then, PEG-SCM $(1 \mathrm{~g})$ was added in PAM-PBLA- $\mathrm{NH}_{2}$ solution. The reaction mixture was stirred for $2 \mathrm{~h}$ at room temperature. Subsequently, the reaction mixture solution was precipitated in 10 -fold excess of precooled $\left(4{ }^{\circ} \mathrm{C}\right)$ diethyl ether $(100 \mathrm{~mL})$. After overnight precipitation at $4{ }^{\circ} \mathrm{C}$, the precipitate was obtained by centrifugation at $3000 \mathrm{rpm}$ for $5 \mathrm{~min}$. The crude precipitate was washed twice with diethyl ether to obtain the precipitate. The precipitate was dried by vacuum evaporation to obtain PAM-PBLA-PEG.

\subsubsection{Synthesis of PAM-PAsp- $b$-PEG}

Third, PAM-PAsp- $b$-PEG was obtained by hydrolysis reaction between PAM-PBLA-PEG and $\mathrm{CF}_{3} \mathrm{COOH}$. Briefly, PAM-PBLA-PEG $(1 \mathrm{~g})$ was dissolved in $\mathrm{CF}_{3} \mathrm{COOH}(10 \mathrm{~mL})$. Hydrogen bromide $(\mathrm{HBr}) /$ acetic acid (HAc) $(1: 2, v / v ; 1 \mathrm{~mL})$ was added to PAM-PBLA-PEG solution. The reaction mixture 
was stirred for $1 \mathrm{~h}$ at room temperature. Subsequently, the reaction mixture was precipitated in 10-fold excess of precooled $\left(4^{\circ} \mathrm{C}\right)$ diethyl ether $(200 \mathrm{~mL})$. After overnight precipitation at $4{ }^{\circ} \mathrm{C}$, the precipitate was obtained by centrifugation at $3000 \mathrm{rpm}$ for $5 \mathrm{~min}$. The precipitate was dissolved in deionized water and was dialyzed against water for 2 days in a dialysis bag with a molecular cutoff of $5 \mathrm{kD}$. The solution was lyophilized to obtain PAM-PAsp-b-PEG.

\subsubsection{Synthesis of PAM-PAspPBA- $b$-PEG}

Fourth, PAM-PAspPBA- $b$-PEG was synthesized by amidation reaction between PAM-PAsp-b-PEG and APBA. Briefly, PAM-PAsp- $b$-PEG (0.5 g) and APBA (0.305 g) were dissolved in DMF (10 mL). EDC ( $2 \mathrm{~g})$ was added to the solution. The mixture solution was magnetically stirred for $4 \mathrm{~h}$ at $4{ }^{\circ} \mathrm{C}$. Subsequently, a 10-fold volume of deionized water $(\mathrm{pH}=3)$ was added, and the precipitate was isolated by centrifugation at $3000 \mathrm{rpm}$ for $10 \mathrm{~min}$. The precipitate was washed with deionized water ( $\mathrm{pH} 7.0)$ and was lyophilized to obtain PAM-PAspPBA- $b$-PEG. The synthesis scheme of PAM-PAspPBA- $b$-PEG is summarized in Scheme 1.

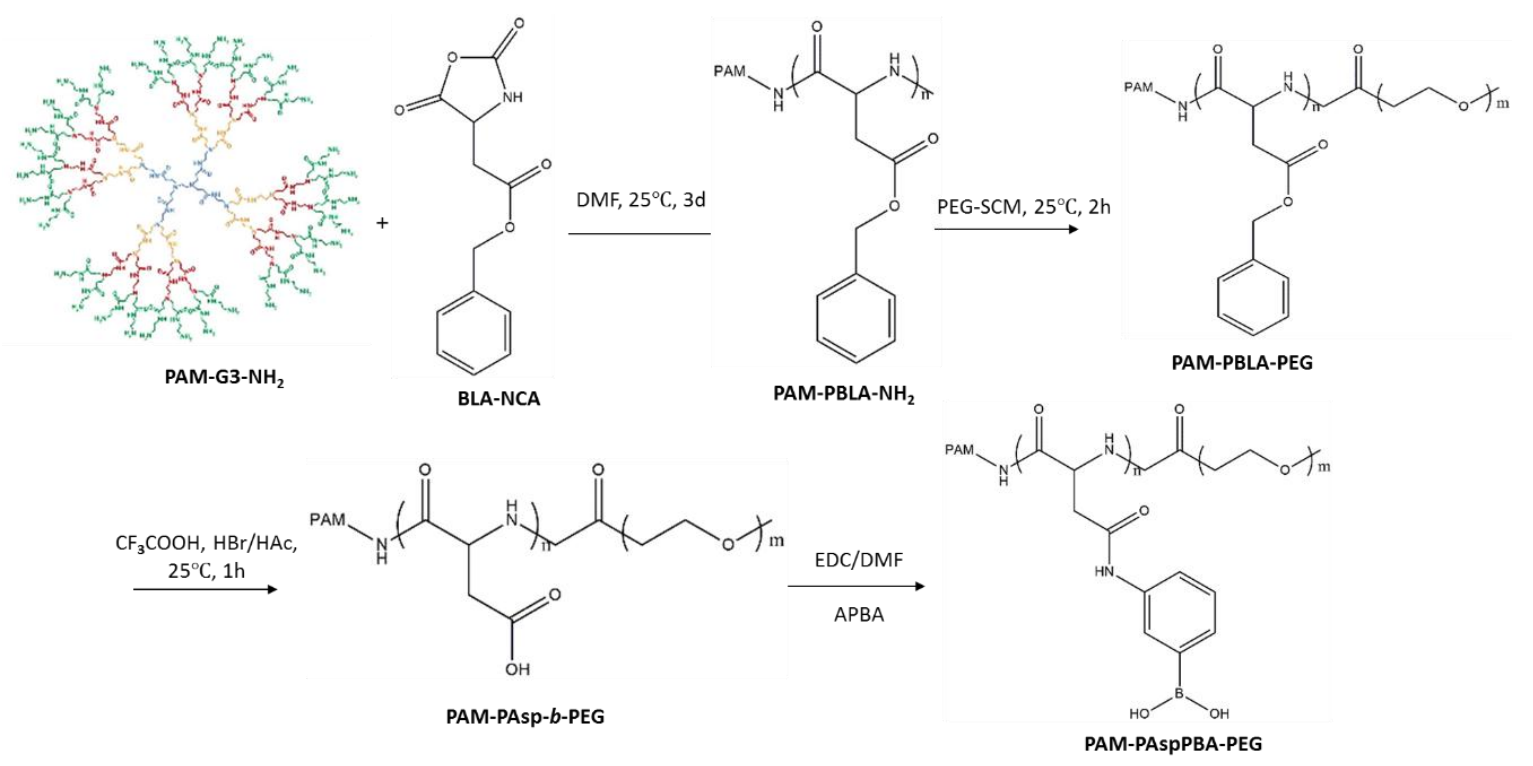

Scheme 1. Synthesis scheme of PAM-PAspPBA- $b$-PEG.

\subsection{Preparation of FITC-Insulin Loaded Micelles}

Fifth, insulin $(20 \mathrm{mg})$ was dissolved in deionized water $(1 \mathrm{~mL}, \mathrm{pH}=2)$. FITC $(2 \mathrm{mg})$ was dissolved in dimethyl sulfoxide (DMSO, $0.2 \mathrm{~mL}$ ). Insulin and FITC solutions were mixed for $12 \mathrm{~h}$ at $4{ }^{\circ} \mathrm{C}$. FITC-insulin was produced and was dialyzed against deionized water for 2 days and was lyophilized. PAM-PAspPBA-b-PEG (20 mg) was dissolved in PBS ( $\mathrm{pH}=12)$ and FITC-insulin (2 mg) was dissolved in PBS ( $\mathrm{pH}=2)$. FITC-insulin solution was added to PAM-PAspPBA- $b$-PEG solution at a rate of six drops per minute until the $\mathrm{pH}$ becomes 6 . A Tyndall effect was observed, and FITC-insulin loading PAM-PAspPBA- $b$-PEG micelles were obtained. These insulin-loading micelles were dialyzed against deionized water for 2 days in a dialysis bag with a molecular cutoff of $5 \mathrm{kD}$.

\subsection{Characterization of Micelles}

\subsection{1. ${ }^{1} \mathrm{H}-\mathrm{NMR}$}

${ }^{1} \mathrm{H}-\mathrm{NMR}$ spectra were obtained on a UNITY-plus $400 \mathrm{M}$ nuclear magnetic resonance spectrometer (Varian, Palo Alto, CA, USA) using chloroform-d $\left(\mathrm{CDCl}_{3}\right)$, heavy water $\left(\mathrm{D}_{2} \mathrm{O}\right)$, and deuterated sodium hydroxide (NaOD) as solvents. Gel permeation chromatography (GPC) measurements of block copolymers were conducted at $35^{\circ} \mathrm{C}$ by using a Waters 1515 chromatography system (Waters, Milford, 
MA, USA) equipped with a Waters 2414 refractive index detector. Tetrahydrofuran (THF) and DMF containing $500 \mathrm{mM}$ lithium bromide ( $\mathrm{LiBr})$ were separately used as eluent at a flow rate of $1 \mathrm{~mL} \mathrm{~min}{ }^{-1}$. Polystyrene standards were employed in calibration.

\subsubsection{TEM Measurements}

TEM measurements were performed by using a commercial T20ST electron microscope (Philips, Amsterdam, Holland) at an acceleration voltage of $200 \mathrm{kV}$. To prepare the TEM samples, a small drop of the micellar solution was deposited on a carbon-coated copper electron microcopy grid and was dried under room temperature and atmospheric pressure.

\subsubsection{DLS measurements}

The structure of the micelles was characterized by DLS measurements. In this study, DLS measurements were performed at $636 \mathrm{~nm}$ by using a laser light scattering spectrometer (BI-200SM, Brookhaven, New York, NY, USA) equipped with a digital correlator (BI-9000AT).

\subsubsection{Insulin Release Study}

About $0.2-1 \mathrm{~mL}$ of FITC-Insulin-loaded micelle solution $(1 \mathrm{mg} / \mathrm{mL}$, calculated by PAM-PAspPBA- $b$ PEG) was injected in a dialysis bag with a molecular weight cutoff of $10 \mathrm{kD}$, and the dialysis bag was placed in 10-30 mL of PBS ( $\mathrm{pH}$ 7.4) with different glucose concentrations $(0,1,3,5,10,20$ and $30 \mathrm{mM}$ ). About $200 \mu \mathrm{L}$ of the dialysis solution was used to measure the insulin concentration at different time points $(0,5,10,20,30,60,120$ and $240 \mathrm{~min})$ by assaying fluorescence intensity (excitation wavelength: $490 \mathrm{~nm}$, emission wavelength: $525 \mathrm{~nm}$ ). This experiment was repeated thrice. Once we took out the dialysis solution for assay, identical volume of PBS should be immediately added to the dialysis solution. We also evaluated the insulin release of the micelle in serum (100\% FBS, pH 7.4) with different glucose concentrations ( 5 and $20 \mathrm{mM})$ at different time points $(0,5,10,20,30$ and $60 \mathrm{~min})$ as described above.

\subsubsection{Safety and Effect Evaluation in Animals}

Male NIH mice (4-week old) were purchased from Guangdong Medical Animal Center (Guangzhou, China). The animals were kept at a room with temperature $20 \pm 2{ }^{\circ} \mathrm{C}$, humidity $60 \% \pm 5 \%$, and $12 \mathrm{~h}$ dark/light cycle. All experiments were strictly in accordance with the recommendations of the Guide for the Care and Use of Laboratory Animals of the Institutional Animal Care and Use Committee of Tsinghua University (No.17-1f1\#). For the safety assay, after acclimation for two weeks, the normal animals were randomly divided into two groups (four mice per group). The first group was subcutaneously injected with insulin-loaded PAM-PAspPBA- $b$-PEG that contained $1.2 \mathrm{mg} / \mathrm{kg}$ insulin. The second group was subcutaneously injected with pure insulin at a dosage of $1.2 \mathrm{mg} / \mathrm{kg}$. The normal animals were analyzed in a fasting condition. The number of animal survivals was recorded after 2 and $4 \mathrm{~h}$ of injection. For diabetic mice, after acclimation for one week, diabetes was induced in mice fasting for $24 \mathrm{~h}$ by intraperitoneal injection of streptozotocin (Sigma-Aldrich, St. Louis, MO, USA; $100 \mathrm{mg} / \mathrm{kg}$ ) according to the previous method [15]. After a week, mice with blood glucose over $11.1 \mathrm{mmol} / \mathrm{L}$ were selected as the diabetic model and subjected into further investigation. The protocol of the safety assay in diabetic mice (five mice per group) was similar to that in normal mice.

For the effect assay, the selected diabetic mice were divided into three groups, where the first group was subcutaneously injected with insulin-loaded PAM-PAspPBA- $b$-PEG that contained $0.25 \mathrm{mg} / \mathrm{kg}$ insulin, the second group was treated with pure insulin at a dosage of $0.25 \mathrm{mg} / \mathrm{kg}$ and the third group was treated with PBS control. In the preliminary experiment, pure PAM-PAspPBA- $b$-PEG did not affect blood glucose (data not shown). The diabetic animals were analyzed in a fasting state. Blood glucose was assayed at $0,15,30,45,60,90,120,240,360,480,660$ and $840 \mathrm{~min}$ by using a glucometer (Roche, Basel, Switzerland). 


\subsection{Cytotoxicity and Inflammatory Factor Assays}

The cytotoxicity assay of PAM-PAspPBA- $b$-PEG was conducted in RAW264.7 cells by MTT method as described previously [6]. Briefly, RAW264.7 cells were seeded into 96-well plate at cell density of 10,000 per well and incubated with DMEM plus 10\% FBS. PAM-PAspPBA- $b$-PEG resuspended in DMEM at final concentrations of 10, 50,100, 200 and $500 \mu \mathrm{g} / \mathrm{mL}$, respectively, were added into the cells. After $24 \mathrm{~h}$ of incubation, $20 \mu \mathrm{L}$ of MTT solution $(5 \mathrm{mg} / \mathrm{mL}$ in PBS buffer) was added to each well. Four hours later, the medium was removed and the samples in the wells were washed with PBS twice. About $100 \mu \mathrm{L}$ of DMSO was added to dissolve the formed crystals for $30 \mathrm{~min}$. The optical density of the solution was measured at $492 \mathrm{~nm}$ using a microplate reader (BioTek Instruments, Inc., Winooski, VT, USA).

In addition, inflammatory factor (IL-6 and TNF- $\alpha$ ) expressions were determined by RT-PCR method as described previously [16]. Briefly, RAW264.7 cells were seeded into 6-well plate at cell density of 250,000 per well and incubated with DMEM plus 10\% FBS. PAM-PAspPBA- $b$-PEG resuspended in DMEM at final concentrations of 50, 200 and $500 \mu \mathrm{g} / \mathrm{mL}$, respectively, were added into the cells. After $24 \mathrm{~h}$ of incubation, total RNA was extracted by using TRIzol reagent (Thermo Fisher Scientific, Waltham, MA, USA) and conduct RT-PCR analysis by using a commercial kit (Takara, Beijing, China). Primers of IL-6 (Forward: CTGCAAGAGACTTCCATCCAG; Reverse GAGTGGTATAGACAGGTCTGTTGG), TNF- $\alpha$ (Forward: GGGCTTCCAGAACTCCA; Reverse: GCTACAGGCTTGTCACTCG), and actin (Forward: GTGACGTTGACATCCGTAAAGA; Reverse: GCCGGACTCATCGTACTCC) were purchased from Thermo Fisher Scientific (Waltham, MA, USA). Actin was used to normalize the values of IL- 6 and TNF- $\alpha$. Relative expressions were calculated as $2^{- \text {ddct }}$.

\subsection{Statistical Analysis}

Data were expressed as mean $\pm \mathrm{SD}$. Statistical significance was evaluated through one-way ANOVA and set as $P<0.05$. When appropriate, Newman-Keuls comparison was used to determine the source of significant differences.

\section{Conclusions}

We successfully synthesized a new material called PAM-PAspPBA- $b$-PEG. The material showed a nanoparticle characterization. The insulin-loaded PAM-PAspPBA- $b$-PEG nanoparticle is glucose responsive, more effective, and safer than pure insulin. This study provides guidance for the future development of smart insulin delivery systems.

Author Contributions: Conceptualization, X.W. and G.L.; Methodology, W.W., G.L. and W.X.; Validation, G.L., W.X. and W.W.; Formal Analysis, W.W., L.L., G.L., F.L. and W.X.; Investigation, W.W., L.L., and X.Z; Resources, Y.Z. and F.L.; Data Curation, W.W; Writing-Original Draft Preparation, W.W., W.X. and G.L.; Writing-Review \& Editing, W.X.; Supervision, W.X; Project Administration, Y.Z.

Funding: This research was funded by the Shenzhen Science and Technology Innovation Committee (GRCK2017042415075836 and JCYJ20170307152357168), the National Natural Science Foundation of China (81373460 and 51703258), and the Guangzhou science technology and innovation commission (201804010309).

Conflicts of Interest: The authors declare no conflict of interest. The funders had no role in the design of the study; in the collection, analyses, or interpretation of data; in the writing of the manuscript, and in the decision to publish the results.

\section{References}

1. Guariguata, L.; Whiting, D.R.; Hambleton, I.; Beagley, J.; Linnenkamp, U.; Shaw, J.E. Global estimates of diabetes prevalence for 2013 and projections for 2035. Diabetes Res. Clin. Pract. 2014, 103, 137-149. [CrossRef] [PubMed]

2. Boyle, M.E. Optimizing the treatment of type 2 diabetes using current and future insulin technologies. Medsurg Nurs. 2008, 17, 383-390. [PubMed] 
3. Kusunoki, Y.; Katsuno, T.; Nakae, R.; Watanabe, K.; Akagami, T.; Ochi, F.; Tokuda, M.; Murai, K.; Miuchi, M.; Miyagawa, J.; et al. Evaluation of blood glucose fluctuation in Japanese patients with type 1 diabetes mellitus by self-monitoring of blood glucose and continuous glucose monitoring. Diabetes Res. Clin. Pract. 2015, 108, 342-349. [CrossRef] [PubMed]

4. Golden, S.H.; Sapir, T. Methods for insulin delivery and glucose monitoring in diabetes: Summary of a comparative effectiveness review. J. Manag Care Pharm. 2012, 18, 1-17. [CrossRef]

5. Guo, X.; Wang, W. Challenges and recent advances in the subcutaneous delivery of insulin. Expert Opin. Drug Deliv. 2017, 14, 727-734. [CrossRef] [PubMed]

6. Liu, G.; Ma, R.; Ren, J.; Li, Z.; Zhang, H.; Zhang, Z.; An, Y.; Shi, L. A glucose-responsive complex polymeric micelle enabling repeated on-off release and insulin protection. Soft Matter 2013, 9, 1636-1644. [CrossRef]

7. Wu, W.; Zhou, S. Responsive materials for self-regulated insulin delivery. Macromol. Biosci. 2013, 13, 1464-1477. [CrossRef] [PubMed]

8. Zhao, L.; Xiao, C.; Wang, L.; Gai, G.; Ding, J. Glucose-sensitive polymer nanoparticles for self-regulated drug delivery. Chem. Commun. 2016, 52, 7633-7652. [CrossRef] [PubMed]

9. Wang, B.; Ma, R.; Liu, G.; Li, Y.; Liu, X.; An, Y.; Shi, L. Glucose-responsive micelles from self-assembly of poly(ethylene glycol)-b-poly(acrylic acid-co-acrylamidophenylboronic acid) and the controlled release of insulin. Langmuir 2009, 25, 12522-12528. [CrossRef] [PubMed]

10. Markowicz-Piasecka, M.; Luczak, E.; Chalubinski, M.; Broncel, M.; Mikiciuk-Olasik, E.; Sikora, J. Studies towards biocompatibility of PAMAM dendrimers-overall hemostasis potential and integrity of the human aortic endothelial barrier. Int. J. Pharm. 2014, 473, 158-169. [CrossRef] [PubMed]

11. Morris, C.J.; Aljayyoussi, G.; Mansour, O.; Griffiths, P.; Gumbleton, M. Endocytic uptake, transport and macromolecular interactions of anionic PAMAM dendrimers within lung tissue. Pharm. Res. 2017, 34, 2517-2531. [CrossRef] [PubMed]

12. Liu, G.; Gao, H.; Zuo, Y.; Zeng, X.; Tao, W.; Tsai, H.I.; Mei, L. DACHPt-loaded unimolecular micelles based on hydrophilic dendritic block copolymers for enhanced therapy of lung cancer. ACS Appl. Mater. Interfaces 2017, 9, 112-119. [CrossRef] [PubMed]

13. Rubin, D.J.; Golden, S.H. Hypoglycemia in non-critically ill, hospitalized patients with diabetes: Evaluation, prevention, and management. Hosp. Pract. (1995) 2013, 41, 109-116. [CrossRef] [PubMed]

14. Murata, M.; Adachi, H.; Oshima, S.; Kurabayashi, M. Glucose fluctuation and the resultant endothelial injury are correlated with pancreatic beta cell dysfunction in patients with coronary artery disease. Diabetes Res. Clin. Pract. 2017, 131, 107-115. [CrossRef] [PubMed]

15. Cui, K.; Zhang, S.; Jiang, X.; Xie, W. Novel synergic antidiabetic effects of astragalus polysaccharides combined with crataegus flavonoids via improvement of islet function and liver metabolism. Mol. Med. Rep. 2016, 13, 4737-4744. [CrossRef] [PubMed]

16. Xu, C.; Wang, W.; Zhong, J.; Lei, F.; Xu, N.; Zhang, Y.; Xie, W. Canagliflozin exerts anti-inflammatory effects by inhibiting intracellular glucose metabolism and promoting autophagy in immune cells. Biochem. Pharm. 2018, 152, 45-59. [CrossRef] [PubMed]

Sample Availability: The sample of the compound PAM-PAspPBA- $b$-PEG is available from the authors.

(C) 2018 by the authors. Licensee MDPI, Basel, Switzerland. This article is an open access article distributed under the terms and conditions of the Creative Commons Attribution (CC BY) license (http:/ / creativecommons.org/licenses/by/4.0/). 